\title{
Method and complex of express diagnostics of liquid packaged products
}

\author{
Valeriy Belozerov, Viktor Martynov*, and Vladimir Belozerov \\ Don State Technical University, Gagarin square 1, 344016 Rostov-on-Don, Russia
}

\begin{abstract}
Annotation. In order to improve the efficiency of quality control and safety of liquid packaged products, a method and model of an automated complex have been developed that allow rapid diagnostics of liquid without opening the container and sampling. The article describes the method, the results of its application in the identification of engine oil and the model of a portable automated complex with sensors-covers for continuous monitoring of bottled water. The data of experimental studies of the models are presented. The obvious result of using the method and the complex, from the point of view of energy saving and energy efficiency, is its application for continuous control of motor and transformer oils, to ensure the technical resource of motor vehicles and transformers at electrical substations, which, according to preliminary estimates, reduces the cost of selective control and losses from unscheduled repairs by 2 times.
\end{abstract}

\section{Introduction}

Quality and safety control of liquid packaged products is an extremely time-consuming process, since the methods and means used are costly and time-consuming, and the selective control method does not guarantee the quality of each individual packaged product in a batch [1-5], which, to prevent counterfeiting, requires a radical change in the policy of supervision and controls, i.e. it is necessary to develop and implement automated methods and means of continuous control of parameters [6].

Both industrial liquid products and household liquids, in addition to the determination of chemical compositions, can be identified by many physical and chemical parameters, for example, by kinematic and dynamic viscosity, by density by standard temperatures, electrical parameters, by characteristic frequencies, etc. [7-9].

\section{Materials and methods}

At manufacturing plants, liquid filling in containers is carried out on automated lines, the advantage of which is high accuracy of dosing [10]. At the same time, the standard for packaging strictly limits the maximum deviations from the nominal size and weight of the

\footnotetext{
*Corresponding author: $89054516201 @$ mail.ru
} 
container [11]. Thus, knowing the mass of empty container, it is possible to weigh, without breaking the tightness of the container, to determine the density of the liquid inside it according to the following formula $[4,5]$ :

where are:

$$
\rho_{i}=\left(P_{i}-P_{j}\right) / V_{i j}
$$

$P_{i}$ - measured weight of the $i$-th sample in a packed container, $\mathrm{kg}$;

$P_{j}$ - weight of the $j$-th reference container, $\mathrm{kg}$;

$V_{i j}=0.5,1.5 \ldots N-$ reference container volume, 1 .

and the values of densities at different temperatures are calculated by the formula $[4,5]$ :

where are:

$$
\rho(t)=\rho_{20^{\circ} \mathrm{C}}-\Delta t \cdot\left(t-20^{\circ} \mathrm{C}\right)
$$

$\rho_{20^{\circ} \mathrm{C}}$ - the density of the liquid at $20^{\circ} \mathrm{C}, \mathrm{g} / \mathrm{cm}^{3}$;

$\Delta t=\left(18,31-13,233 \cdot \rho_{20^{\circ} \mathrm{C}}\right) \cdot 10^{-4}$ - temperature correction to density by one degree;

$t$ - the desired temperature, ${ }^{\circ} \mathrm{C}$;

Also, the dependence of the kinematic viscosity on the temperature is expressed by the formula $[4,5]$ :

$$
\lg \lg (v+0,8)=a+b \lg T,
$$

where the empirical coefficients a and $\mathrm{b}$ are determined from the known pairs of values $v$ and $T$ by the formulas:

$$
a=\lg \lg \left(v_{1}+0,8\right)-b \lg T_{1}, \quad b=\frac{\lg \left(\lg \left(v_{1}+0,8\right) / \lg \left(v_{1}+0,8\right)\right)}{\lg \frac{T_{1}}{T_{2}}} .
$$

On the other hand, the simplest method for determining the transport function in the study of an electrochemical system is to excite it with a signal in the form of a sinusoidal wave $[12,13]$. This method uses the conductivity relations in liquids, which are described by Ohm's laws (Z, G, R, I). In addition to determining the specific parameters of samples and standards, the main equation of the characteristic impedance can be used $[4,5]$ :

$$
Z_{i}=\sqrt{\frac{R_{i}+i \omega L_{i}}{G_{i}+i \omega C_{i}}}
$$

where are:

$Z_{i}$ - complex resistance;

$\omega=2 \pi f-$ cyclic frequency;

$i$ - imaginary unit;

$R_{i}$ - resistance;

$L_{i}$ - inductance;

$G_{i}$ - conductivity;

$C_{i}$ - capacitance.

By solving the impedance equation (5), additional parameters can be obtained for sample identification, in particular, for determining the magnetic permeability of a liquid using the formula $[4,5]$ :

where are:

$$
\mu=\frac{Z^{2} \cdot 2 l}{S \cdot G \cdot(1+i)^{2} \cdot \mu_{0} \cdot \omega}
$$

$\mu_{0}$ - magnetic constant;

$\mathrm{S}$ - surface area of the electrode, $\mathrm{m}^{2}$;

$l$-distance between measuring electrodes, $\mathrm{m}$. 
In turn, the permittivity can be determined by changing the tangent of the loss angle and the conductivity $[4,5]$ :

where are:

$$
\varepsilon=\varepsilon^{\prime}-i \varepsilon^{\prime \prime} \rightarrow \operatorname{tg} \delta=\frac{\varepsilon^{\prime \prime}}{\varepsilon^{\prime}}=\frac{\sigma}{\omega \varepsilon^{\prime \varepsilon_{0}}}
$$

$\varepsilon-$ relative dielectric permittivity;

$\varepsilon^{\prime \prime}$ - imaginary part of the permittivity;

$\varepsilon^{\prime}-$ real part of the permittivity;

$\sigma$ - active conductivity, taking into account both types of losses;

$\varepsilon_{0}$ - permittivity of vacuum.

Then, using the Debye formula $[4,5]$, the relaxation times are determined: macroscopic and microscopic:

where are:

$$
\varepsilon^{\prime \prime}=\frac{\left(\varepsilon-\varepsilon_{\infty}\right) \omega \tau}{1+\omega^{2} \tau^{2}}, \quad \varepsilon^{\prime}=\varepsilon_{\infty}+\frac{\varepsilon-\varepsilon_{\infty}}{1-\omega^{2} \tau^{2}}, \quad \operatorname{tg} \delta=\frac{\varepsilon^{\prime \prime}}{\varepsilon^{\prime}}=\frac{\left(\varepsilon-\varepsilon_{\infty}\right) \omega \tau}{\varepsilon+\varepsilon_{\infty} \omega^{2} \tau^{2}}
$$

$\tau$ - macroscopic relaxation time.

The complex part of the permittivity $\varepsilon^{\prime \prime}$ tends to zero, both at small and large values of $w \tau$, and reaches a maximum at $\omega_{m} \tau=1[4,5]$, in which

and the complex dielectric conductivity is equal to

$$
\varepsilon_{m}^{\prime \prime}=\frac{\varepsilon-\varepsilon_{\infty}}{2}, \quad \varepsilon_{m}^{\prime}=\frac{\varepsilon+\varepsilon_{\infty}}{2}
$$

where are:

$$
\varepsilon^{*}=\varepsilon_{m}+\frac{\left(\varepsilon-\varepsilon_{\infty}\right)}{1+i \omega\left(\frac{\varepsilon+2}{\varepsilon_{\infty}+2}\right) \tau_{\mu}}
$$

$\tau_{\mu}-$ microscopic relaxation time.

The relation of the microscopic relaxation time to the macroscopic time is expressed by the Pauls equation $[4,5]$ :

$$
\tau=\frac{3 \varepsilon \tau_{\mu}}{2 \varepsilon+1}
$$

then, from the point of view of comparing any reference liquid with the one under study, we can use the ratio of the specified times, which according to Debye are related to their viscosity coefficients $-\eta_{i}$, by a simple ratio $[4,5]$ :

$$
\tau_{\mu 2}=\tau_{\mu 1}\left(\frac{\eta_{2}}{\eta_{1}}\right)
$$

Thus, instead of determining the kinematic viscosity of the liquid product $(v)$ using a viscometer, and then calculating the dynamic viscosity $(\eta)$ by determining its density $(\rho)$, one can first determine the dynamic viscosity from the change in dielectric constant and from the ratio of microscopic relaxation times with the reference liquid product, including taking into account the temperature and frequency, and then calculate the kinematic viscosity of the liquid by the formula $[4,5]$ :

$$
v=\frac{\eta}{\rho}
$$

\section{Results and discussion}

The developed method was used to create "reference images" (Table 1), and then to detect and identify counterfeit products in 3 batches of Castrol Magnatec engine oil, with a total volume of 3,500 cans, as follows: 
Table 1. Reference images of Castrol Magnatec engine oil.

\begin{tabular}{|c|c|c|c|c|c|c|c|c|c|}
\hline $\mathrm{T},{ }^{\circ} \mathrm{C}$ & $\mathrm{m}, \mathrm{g}$ & $\rho, \mathrm{g} / \mathrm{cm}^{3}$ & $\eta, \mathrm{Pa} \cdot \mathrm{s}$ & $v, \mathrm{~m}^{2} / \mathrm{s}$ & $\varepsilon$ & $\operatorname{tg} \sigma$ & $\mathrm{Cp}, \mathrm{pF}$ & $\tau, \mathrm{s}$ & $\tau_{\mu}, \mathrm{s}$ \\
\hline \multicolumn{10}{|c|}{ SW-30 A3/B4 4L } \\
\hline 22 & \multirow{6}{*}{3643} & 0,8520 & 130,52 & 153,19 & 2,9344 & 0,01510 & \multirow{6}{*}{26,3} & 0,009578 & 0,007473 \\
\hline 15 & & 0,8541 & 187,73 & 219,79 & 2,8858 & 0,01474 & & 0,009583 & 0,012252 \\
\hline 40 & & 0,8365 & 58,55 & 69,50 & 3,0593 & 0,01608 & & 0,009535 & 0,012293 \\
\hline 100 & & 0,7942 & 9,61 & 12,15 & 3,4758 & 0,02000 & & 0,009121 & 0,011961 \\
\hline-30 & & 0,8859 & 5900,70 & 6660,16 & 2,5735 & 0,01267 & & 0,009443 & 0,011861 \\
\hline-45 & & 0,8964 & 8964,45 & 10000,00 & 2,4694 & 0,01206 & & 0,009330 & 0,011638 \\
\hline \multicolumn{10}{|c|}{$5 \mathrm{~W}-30 \mathrm{AP} 4 \mathrm{~L}$} \\
\hline 22 & \multirow{6}{*}{3629} & 0,8483 & 122,80 & 144,76 & 2,8718 & 0,01660 & \multirow{6}{*}{25,9} & 0,008558 & 0,006698 \\
\hline 15 & & 0,8504 & 178,24 & 209,60 & 2,8381 & 0,01633 & & 0,000274 & 0,000214 \\
\hline 40 & & 0,8326 & 49,96 & 60,59 & 2,9588 & 0,17310 & & 0,000077 & 0,000060 \\
\hline 100 & & 0,7900 & 8,69 & 11,10 & 3,2486 & 0,02000 & & 0,000013 & 0,000010 \\
\hline-30 & & 0,8824 & 6344,70 & 7189,87 & 2,6207 & 0,14760 & & 0,009738 & 0,007622 \\
\hline-36 & & 0,8866 & 8866,15 & 10000,00 & 2,5918 & 0,01456 & & 0,008472 & 0,010652 \\
\hline \multicolumn{10}{|c|}{$5 \mathrm{~W}-30 \mathrm{~A} 54 \mathrm{~L}$} \\
\hline 22 & \multirow{6}{*}{3627} & 0,8490 & 123,60 & 145,58 & 2,7394 & 0,15000 & \multirow{6}{*}{25,7} & 0,008819 & 0,006952 \\
\hline 15 & & 0,8411 & 182,69 & 217,20 & 2,7086 & 0,01460 & & 0,008881 & 0,007001 \\
\hline 40 & & 0,8334 & 45,00 & 54,36 & 2,8188 & 0,01600 & & 0,008644 & 0,006784 \\
\hline 100 & & 0,7908 & 7,59 & 9,65 & 3,0833 & 0,02000 & & 0,007936 & 0,006148 \\
\hline-30 & & 0,8831 & 9600,70 & 10871,35 & 2,5102 & 0,01260 & & 0,009186 & 0,007343 \\
\hline-39 & & 0,8894 & 8894,39 & 10000,00 & 2,4705 & 0,01220 & & 0,009225 & 0,007394 \\
\hline \multicolumn{10}{|c|}{$5 \mathrm{~W}-40 \mathrm{~A} 3 / \mathrm{B} 44 \mathrm{~L}$} \\
\hline 22 & \multirow{6}{*}{3625} & 0,8490 & 136,38 & 160,63 & 3,2445 & 0,01700 & \multirow{6}{*}{29} & 0,009757 & 0,007507 \\
\hline 15 & & 0,8511 & 194,42 & 228,42 & 3,1768 & 0,01676 & & 0,009629 & 0,007429 \\
\hline 40 & & 0,8334 & 66,59 & 80,09 & 3,4185 & 0,01765 & & 0,010062 & 0,007689 \\
\hline 100 & & 0,7908 & 10,44 & 13,30 & 3,9987 & 0,02000 & & 0,010824 & 0,008118 \\
\hline-30 & & 0,8831 & 5440,70 & 6160,43 & 2,7417 & 0,01528 & & 0,008690 & 0,006849 \\
\hline-48 & & 0,8958 & 8958,24 & 10000,00 & 2,5677 & 0,01473 & & 0,008344 & 0,006645 \\
\hline
\end{tabular}

- each oil canister was weighed with an ambient temperature measurement, after which the oil densities were calculated for the current and for the standards temperatures $\left(15^{\circ} \mathrm{C}\right.$, $40^{\circ} \mathrm{C}, 100^{\circ} \mathrm{C}$ );

- each oil canister was opened, the electrical parameters of the oil and the sensor capacity were measured, and their dynamic viscosities were calculated at ambient temperature and at standard temperatures;

- based on the obtained densities and dynamic viscosities, the kinematic viscosities of oils were calculated;

- according to the Walter formulas, the indices of the viscosity of oils and their pour point were calculated. 
Thus, in 3 batches with a total volume of 3,500 canisters ( 1 and 3 liters), a fake of Castrol Magnatec engine oil was determined by Rosneft engine oil [5].

Further studies of packaged non-alcoholic products showed the effectiveness of the developed method and the possibility of its implementation, through the development and production of sensor caps (Fig. 1), as well as portable automated express control systems [3].

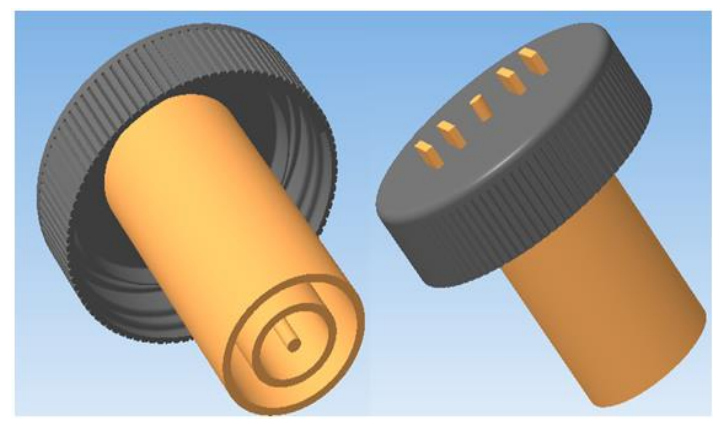

Fig. 1. 3D model of the prototype sensor-cover

Under the control of a computer, the immitance meter is connected to the contact pad of the sensor-cover of the packed liquid product, which is placed on the scale, to determine the mass of the liquid $(P)$ and its density $(\rho)$, first the parameters of the gas medium (air with liquid vapor) inside the container are measured, and after turning and installing the packed liquid product with the contact plate on the electronic scale - again, the mass and density, as well as the parameters of liquid: sensor-cover capacitance $(C p)$, resistance $(R p)$, electrical conductivity $(G p)$, loss angle tangent $(\operatorname{tg} \delta)$, and leakage current $(I)$ at fixed frequencies from 10 to $1,000,000 \mathrm{~Hz}$. In this case, the obtained data form the spectra of values that are used for the subsequent calculation of the relative permittivity $(\varepsilon)$, macroscopic relaxation time $(\tau)$, molecular relaxation time $\left(\tau_{\mu}\right)$, dynamic $(\eta)$ and kinematic viscosity $(v)$ [3-5].

The key elements of the portable automated complex (Fig. 2) are an immitance meter, an electronic scale with a temperature sensor, a laptop and special software (SPO) that implements control and computational algorithms [3-5].

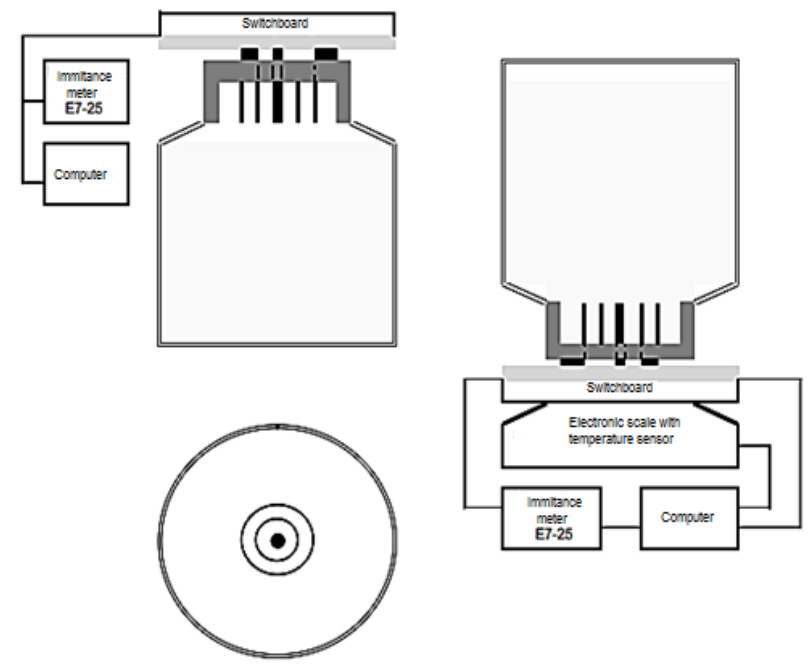

Fig. 2. Structure of the complex 
Table 2. Measured parameters of the gas medium at $22^{\circ} \mathrm{C}$

\begin{tabular}{|c|c|c|c|c|c|}
\hline \multirow{2}{*}{$f, H z$} & \multicolumn{5}{|c|}{ MEASURED PARAMETERS } \\
\cline { 2 - 5 } & $C p, p F$ & $R p, O m$ & $G p, n S$ & tgd $(D C)$ \\
\hline 60 & 1050 & 458483 & 2171 & 5,5 & 5,72 \\
\hline 120 & 545 & 424537 & 2352 & 5,95 \\
\hline 240 & 281 & 395422 & 2520 & 6,08 \\
\hline 480 & 148 & 369647 & 2710 & 5,93 \\
\hline 960 & 81 & 345962 & 2892 & 5,27 \\
\hline 2000 & 46 & 325017 & 3079 & 4,11 \\
\hline 4000 & 32 & 306603 & 3263 & 2,9 \\
\hline 8000 & 24 & 289248 & 3457 & 1,86 \\
\hline 16000 & 20 & 270317 & 3691 & 1,16 \\
\hline 32000 & 17 & 244983 & 4106 & 0,71 \\
\hline 64000 & 15 & 232983 & 4289 & 0,4 \\
\hline 125000 & 15 & 211783 & 4745 & 0,24 \\
\hline 250000 & 14 & 182267 & 5485 & 0,15 \\
\hline 500000 & 14 & 151500 & 6621 & 8,11 \\
\hline 1000000 & 14 & 101183 & 9893 & \\
\hline
\end{tabular}

Table 3. Measured water parameters at 22 and $44^{\circ} \mathrm{C}$

\begin{tabular}{|c|c|c|c|c|c|c|c|c|c|c|}
\hline \multirow{3}{*}{$f, H z$} & \multicolumn{10}{|c|}{ MEASURED PARAMETERS } \\
\hline & \multicolumn{2}{|c|}{$C p, p F$} & \multicolumn{2}{|c|}{$\mathrm{Rp}, \mathrm{Om}$} & \multicolumn{2}{|c|}{$G p, n S$} & \multicolumn{2}{|c|}{$\operatorname{tg} \sigma$} & \multicolumn{2}{|c|}{$I, m A(D C)$} \\
\hline & $22^{\circ} \mathrm{C}$ & $44^{\circ} \mathrm{C}$ & $22^{\circ} \mathrm{C}$ & $44^{\circ} \mathrm{C}$ & $22^{\circ} \mathrm{C}$ & $44^{\circ} \mathrm{C}$ & $22^{\circ} \mathrm{C}$ & $44^{\circ} \mathrm{C}$ & $22^{\circ} \mathrm{C}$ & $44^{\circ} \mathrm{C}$ \\
\hline 60 & 221383 & 594733 & 8906 & 1664 & 110810 & 590440 & 1,32 & 2,67 & \multirow{15}{*}{ 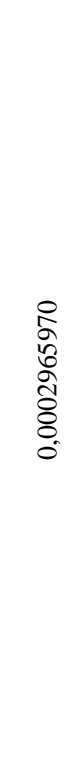 } & \multirow{15}{*}{ 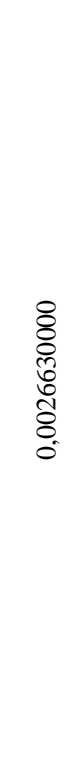 } \\
\hline 120 & 171282 & 388265 & 6268 & 1418 & 150438 & 709043 & 1,22 & 2,39 & & \\
\hline 240 & 128470 & 261712 & 4159 & 1187 & 236390 & 836245 & 1,23 & 2,13 & & \\
\hline 480 & 85062 & 174217 & 2745 & 965 & 360074 & 1038300 & 1,41 & 1,97 & & \\
\hline 960 & 49005 & 109500 & 1878 & 760 & 527272 & 1316483 & 1,79 & 1,99 & & \\
\hline 2000 & 21971 & 57982 & 1407 & 587 & 504576 & 1659775 & 2,56 & 2,34 & & \\
\hline 4000 & 9082 & 27388 & 1178 & 480 & 841530 & 2080550 & 3,7 & 3,02 & & \\
\hline 8000 & 3582 & 11190 & 1055 & 419 & 941214 & 2386550 & 5,25 & 4,24 & & \\
\hline 16000 & 1477 & 4186 & 980 & 386 & 1012640 & 2588960 & 6,84 & 6,15 & & \\
\hline 32000 & 707 & 1572 & 927 & 370 & 1071500 & 2704500 & 7,56 & 8,55 & & \\
\hline 64000 & 426 & 687 & 888 & 362 & 1121300 & 2765250 & 6,55 & 10 & & \\
\hline 125000 & 328 & 404 & 857 & 359 & 1161300 & 2790920 & 4,51 & 8,78 & & \\
\hline 250000 & 292 & 311 & 819 & 358 & 1212700 & 2808467 & 2,65 & 5,74 & & \\
\hline 500000 & 280 & 281 & 775 & 352 & 1283920 & 2842250 & 1,46 & 3,22 & & \\
\hline 1000000 & 260 & 275 & 726 & 335 & 1372720 & 2988220 & 0,84 & 1,72 & & \\
\hline
\end{tabular}


Table 4. Calculated water parameters at $22^{\circ} \mathrm{C}$

\begin{tabular}{|c|c|c|c|c|c|}
\hline \multirow{2}{*}{$f, H z$} & \multicolumn{5}{|c|}{ CALCULATED PARAMETERS } \\
\cline { 2 - 6 } & $e$ & $\tau, s$ & $\tau_{\mu} s$ & $\eta \cdot \bullet 10^{6}, \mathrm{~Pa} \cdot s$ & $v \cdot 10^{6}, \mathrm{~m}^{2} s$ \\
\hline 60 & 210,7 & 0,4176088 & 0,27906633 & 36094898 & 36159,99 \\
\hline 120 & 314,2 & 0,3394552 & 0,22666354 & 61070598 & 61180,72 \\
\hline 240 & 457,3 & 0,2445432 & 0,16320705 & 91458807 & 91623,73 \\
\hline 480 & 575,7 & 0,1344113 & 0,08968538 & 102656627 & 102841,74 \\
\hline 960 & 606,3 & 0,0556805 & 0,03715096 & 82918423 & 83067,95 \\
\hline 2000 & 472,5 & 0,0144325 & 0,00963185 & 39830990 & 39902,82 \\
\hline 4000 & 287,8 & 0,002926 & 0,00195408 & 12602933 & 12625,66 \\
\hline 8000 & 150,8 & 0,0004291 & 0,00028702 & 2607721 & 2612,42 \\
\hline 16000 & 74,98 & 0,0000537 & 0,00003609 & 422004 & 422,77 \\
\hline 32000 & 40,43 & 0,0000129 & 0,00000876 & 127500 & 127,73 \\
\hline 64000 & 28,26 & 0,0000051 & 0,00000351 & 62418 & 62,53 \\
\hline 125000 & 21,78 & 0,0000029 & 0,000002 & 38858 & 38,93 \\
\hline 250000 & 20,15 & 0,0000023 & 0,00000157 & 37058 & 37,13 \\
\hline 500000 & 19,66 & 0,0000034 & 0,00000238 & 69045 & 69,17 \\
\hline 1000000 & 17,94 & 0,000003 & 0,0000021 & 89094 & 89,25 \\
\hline
\end{tabular}

Table 5. Calculated water parameters at $44^{\circ} \mathrm{C}$

\begin{tabular}{|c|c|c|c|c|c|}
\hline \multirow{2}{*}{$f, H z$} & \multicolumn{5}{|c|}{ CALCULATED PARAMETERS } \\
\cline { 2 - 6 } & $e$ & $\tau, s$ & $\tau_{\mu}, s$ & $\eta \cdot \bullet 10^{6}, \mathrm{~Pa} \cdot s$ & $v \cdot 10^{6}, \mathrm{~m}^{2} / \mathrm{s}$ \\
\hline 60 & 656,05 & 0,4539641 & 0,3028734 & 39174143 & 39244,78 \\
\hline 120 & 846,89 & 0,32216979 & 0,21490666 & 57902911 & 58007,32 \\
\hline 240 & 1139,13 & 0,23926722 & 0,15958149 & 89427098 & 89588,36 \\
\hline 480 & 1475,69 & 0,3377767 & 0,22526076 & 257840369 & 258305,32 \\
\hline 960 & 1795,42 & 0,20884705 & 0,13927014 & 310841543 & 311402,07 \\
\hline 2000 & 1848,5 & 0,09147687 & 0,06100107 & 252260232 & 252715,12 \\
\hline 4000 & 1504,12 & 0,03097409 & 0,02065626 & 133223406 & 133463,64 \\
\hline 8000 & 983,3 & 0,00789306 & 0,00526472 & 47833328 & 47919,58 \\
\hline 16000 & 531,04 & 0,00158892 & 0,00106028 & 12397765 & 12420,12 \\
\hline 32000 & 253,17 & 0,00014513 & 0,00009694 & 1411317 & 1413,86 \\
\hline 64000 & 123,47 & 0,00002727 & 0,00001825 & 324259 & 324,84 \\
\hline 125000 & 57,1 & 0,00000549 & 0,00000369 & 71802 & 71,93 \\
\hline 250000 & 32,53 & 0,00000164 & 0,00000111 & 26134 & 26,18 \\
\hline 500000 & 23,76 & 0,00000083 & 0,00000056 & 16295 & 16,33 \\
\hline 1000000 & 20,68 & 0,0000006 & 0,00000041 & 17518 & 17,55 \\
\hline
\end{tabular}

According to the control program, 6 parameter measurements were made at the following frequencies: $60,120,240,480,960,2000,4000,8000,16000,32000,64000$, 
125000, 250000, 500000 and $1000000 \mathrm{~Hz}$. Distilled water was used as the test liquid. The measurements were carried out at 22 and $44^{\circ} \mathrm{C}$. Table 2, 3, 4, and 5 show the data averaged for each frequency.

The set of measured and calculated parameters forms an "image"of the liquid under study, which is subsequently compared with the" image " of the reference.

The final identification of bottled water, as well as its compliance with the established quality and quantity parameters, is carried out taking into account the permissible deviations established by the relevant standards and specifications for packaged liquid products and their containers.

\section{Conclusion}

To carry out continuous control of liquid packaged products and, thereby, to prevent $100 \%$ counterfeit products, it is necessary, first, to develop and put into production sensors-covers on the packaging in which the product is produced, second, at the packaging stage, to install sensors-covers and perform express diagnostics of each product using a portable automated complex, third, to form a base of "reference images" of the packaged liquid products produced (according to manufacturers), fourth, "arm" all chain stores with portable automated systems, for mandatory input control of each packaged product (bottles, cans, etc.), and fifth, organize a subsystem of state and public supervision. [3, 4].

It should be noted that the portable automated system significantly reduces the time of diagnosis, has high mobility, takes into account the conditions of identification, does not require highly qualified personnel, and also for the analysis it is not necessary to withdraw the product from sale, open the container and take a sample, which will favorably affect the overall efficiency, as it will reduce the cost of laboratory control, increasing its frequency.

The obvious result of energy saving and energy efficiency of using the method and the complex is its application for continuous control of motor and transformer oils, to ensure the technical resource of motor vehicles and transformers at electrical substations, which, according to preliminary estimates, reduces the cost of selective control and losses from unscheduled repairs by 2 times.

\section{References}

1. Averina, Yu. M., Vetrova, M. A., Rybina, E. O., Chumakova, A. A. Advances in chemistry and chemical technology 33, 3(213), 25-27 (2019)

2. Buymova, S.A., Bubnov, A.G. Control of product quality, 5, 45-50 (2019)

3. Martynov V. V., Belozerov V. V. European journal of Natural History, 1 66-71 (2021)

4. Belozerov V.V., Lukyanov A.D., Obukhov P.S., Abrosimov D. V. Method of express analysis of liquid packaged products and installation for its implementation. Patent RF, no. 2696810 (2019)

5. Belozerov V. V., Kudryavtsev Yu. A., Plakhotnikov Yu. G. Research of a batch of packaged castrol magnatec motor oil for determining counterfeit products / report on research and development No. 2015/12 of 23.03.2015 (LLC "POLYEXPERT") http://elibrary.ru/item.asp?id=24555474 (accessed 08 May 2021)

6. Transcript of the State Council Presidium meeting on the development of the national consumer protection system (2017). Available at: http://kremlin.ru/events/president/transcripts/deliberations/54328 (accessed 8 May 2021)

7. Babenko V. A., Vasilyeva L. K., Ivanova Z. D., Igolkin B. I., Kartashov Yu. I., Kiryanov V. I., Usikov A. S., Usikov S. V. Method for determining the mass fraction 
of water in oil and residual distillation products by measuring the permittivity at different frequencies. Patent RF, no. 2192001, (2001)

8. Zrelov V. N., Alatortsev E. I., Shatalov K. V., Zrelova L. V., Bordyugovskaya L. N. Method of express determination of kinematic viscosity of aviation kerosene and diesel fuels. Patent RF, no. 2263301, (2004)

9. Bogachev I. M., Bogacheva N. A., Vylegzhanin V. V., Igolkin B. I., Kartashov Yu. I., Petkau O. G., Usikov S. V., Chernova L. I. Device for diagnosing the state of oils and refined products by their active electrical conductivity and dielectric permittivity. Patent RF, no. 2209422, (2002)

10. Catalog of equipment of the group of companies "RESOURCE". Available at: http://aquaresurs.ru/catalog/61/ (accessed 08 May 2021)

11. State Standart 52620-2006. Transport polymer packaging. General technical conditions. (2008)

12. Zolotov V. A., Bartko R. V., Kuznetsov A.V. Definition of operational groups of motor oils". Trudy 25 GosNII MO RF [Proceedings of the 25 State Research Institute of the Ministry of Defense of the Russian Federation] (2006)

13. Conductometry-Chemical Encyclopedia. Available http://encdic.com/enc_chemistry/Konduktometrija-1233/ (accessed 08 May 2021) 